\title{
Pengaruh Gaya Kepemimpinan, Motivasi Kerja Dan Lingkungan Kerja Terhadap Kepuasan Kerja Karyawan Pada PT. Karwikarya Wisman Graha Tanjungpinang
}

\author{
Misdiana, Iranita, Roni Kurniawan \\ Fakultas Ekonomi Universitas Maritim Raja Ali Haji, Tanjungpinang, Kepulauan Riau, Indonesia
}

\begin{abstract}
ABSTRAK: Penelitian ini bertujuan untuk mengetahui gaya kepemimpinan, motivasi kerja dan lingkungan kerja terhadap kepuasan kerja karyawan pada PT. Karwikarya Wisman Graha Tanjungpinang. Metode penelitian yang digunakam yaitu metode statistic deskriptif dengan pendekatan bersifat kuantitatif. Teknik pengumpulan data dilakukan dengan cara observasi dan kuesioner. Jumlah sampel penelitian yang digunakan adalah 115 responden. Analisis data yang digunakan yaitu analisis regresi linier berganda, pengujian hipotesis dalam bentuk uji T dan uji F serta analisis koefisien determinasi. Penelitian yang dilakukan menghasilkan gaya kepemimpinan berpengaruh signifikan terhadap kepuasn kerja karyawan pada PT. Karwikarya Wisman Graha Tanjungpinang karena nilai $\mathrm{t}_{\text {hitung }}>\mathrm{t}_{\text {tabel }}$ atau 3,171 > 1,981 dan nilai signifikansi yang dihasilkan 0,002<0,05. Motivasi kerja berpengaruh signifikan terhadap kepuasn kerja karyawan pada PT. Karwikarya Wisman Graha Tanjungpinang karena nilai $\mathrm{t}_{\text {hitung }}>\mathrm{t}_{\text {tabel }}$ atau 2,366 > 1,981 dan nilai signifikansi yang dihasilkan $0,020<0,05$. Lingkungan kerja berpengaruh signifikan terhadap kepuasn kerja karyawan pada PT. Karwikarya Wisman Graha Tanjungpinang karena nilai $\mathrm{t}_{\text {hitung }}>\mathrm{t}_{\text {tabel }}$ atau 7,168 > 1,981 dan nilai signifikansi yang dihasilkan 0,000<0,05.
\end{abstract}

Kata Kunci : Gaya Kepemimpinan, Motivasi Kerja, Lingkungan Kerja dan Kepuasan Kerja

ABSTRACT: This study aims to determine the leadership style, work motivation and work environment towards employee job satisfaction at PT. Karwikarya Wisman Graha Tanjungpinang. The research method used is descriptive statistical method with a quantitative approach. Data collection techniques are carried out by observation and questionnaire. The number of research samples used was 115 respondents. Analysis of the data used is multiple linear regression analysis, hypothesis testing in the form of $T$ test and $F$ test and analysis of the coefficient of determination. The research conducted resulted in a leadership style that had a significant effect on employee satisfaction at PT. Karwikarya Graha Tanjungpinang because the value of $t$ count $>t$ table or $3.171>1.981$ and the significance value produced is $0.002<0.05$. Work motivation has a significant effect on employee satisfaction at PT. Karwikarya Graha Tanjungpinang because the value of $t$ count $>t$ table or 2,366> 1,981 and the significance value produced is $0.020<0.05$. The work environment has a significant effect on employee satisfaction at PT. Karwikarya Graha Tanjungpinang because the value of $t$ count $>t$ table or $7.168>$ 1.981 and the significance value produced is $0,000<0.05$.

Keywords: Leadership Style, Work Motivation, Work Environment and Job satisfaction

Email Address : misdiana@gmail.com 


\section{PENDAHULUAN}

Di era globalisasi ini, setiap organisasi perusahaan harus mampu dan bertahan dalam persaingan global. Oleh karena itu, setiap perusahaan diharuskan untuk melakukan dinamika perubahan. Strategi untuk selalu dapat bersaing adalah dengan cara memperkuat kapasitas organisasi dan sumber daya manusia yang dimiliki, dengan melakukan perubahanperubahan yang mempersempit kelemahan perusahaan, sehingga menciptakan keunggulankeunggulan yang dapat mempertahankan perusahaan dalam persaingan. Sumber daya manusia merupakan salah satu faktor yang sangat strategis dan fundamental untuk mencapai tujuan tersebut.

Sumber daya manusia merupakan penggerak yang paling utama dalam suatu perusahaan, dalam hal ini adalah perkerja/ karyawan, karena karyawan merupakan aset utama sebagai pemikir, perencana dan pengendali dalam aktivitas sebuah perusahaan.Peranan sumber daya manusia sangat menentukan keberhasilan atau kegagalan organisasi dalam mencapai visi dan misi yang telah ditetapkan.

Kepuasan kerja karyawan harus didukung dengan adanya sarana dan prasarana yang memadai agar mampu menciptakan kegiatan organisasi yang lebih maksimal. Dan yang tidak kalah penting, perusahaan harus selalu memperhatikan kepuasan karyawan agar kinerja mereka dapat terus meningkat.Semakin tinggi tingkat kepuasan karyawan, diharapkan semakin tinggi pula kinerja mereka. Kepuasan kerja adalah keadaan sikap emosional yang menyenangkan atau tidak menyenangkan bagi para karyawan dalam memandang pekerjaannya. Kepuasan kerja mengambarkan perasaan seseorang terhadap pekerjaannya. Sutrisno (2012 : 75)

Berbicara tentang kepuasan karyawan, ada banyak hal yang mempengaruhinya, tiga diantaranya adalah gaya kepemimpinan, motivasi kerja dan lingkungan kerja.
Kepemimpinan merupakan kemampuan untuk mempengaruhi suatu kelompok demi pencapaian tujuan (Robbins, 2008). Gaya kepemimpinan merupakan norma perilaku yang digunakan oleh seseorang pada saat orang tersebut mencoba mempengaruhi perilaku orang lain seperti yang diinginkan. Dalam organisasi, kepuasan karyawan terhadap suatu gaya kepemimpinan akan sangat diperlukan, untuk meningkatkan kinerja mereka sehingga diharapkan akan menghasilkan produktivitas yang tinggi.

Jika seorang pemimpin mampu mempengaruhi para bawahannya untuk bertindak sesuai dengan visi, misi dan tujuan perusahaan, mampu memberikan wawasan, membangkitkan kebanggaan, serta menumbuhkan sikap hormat dan kepercayaan dari karyawannya, hal ini menandakan bahwa segenap karyawannya telah merasa puas atas gaya kepemimpinannya.

Selanjutnya faktor lain yang dapat mempengaruhi kepuasan karyawan adalah motivasi. Motivasi adalah hasrat, keinginan, harapan, tujuan, sasaran, kebutuhan, dorongan, motivasi dan insentif. Motivasi adalah proses yang dimulai dengan defisensi fisiologis yang menggerakkan perilaku atau dorongan yang ditunjukkan untuk tujuan atau insentif. Luthans (2006: 270 )

Setiap kegiatan yang dilakukan oleh seseorang didorong oleh suatu kekuasaan dalam diri orang tersebut, kekuatan pendorong inilah yang disebut motivasi. Motivasi kerja karyawan dalam suatu organisasi dapat dianggap sederhana dan dapat pula menjadi masalah yang kompleks, karena pada dasarnya manusia mudah untuk dimotivasi dengan memberikan apa yang menjadi keinginannya. Masalah motivasi kerja dapat menjadi sulit dalam menentukan imbalan dimana apa yang dianggap penting bagi seseorang karena sesuatu yang penting bagi seseorang belum tentu penting bagi orang lain. Bila seseorang

termotivasi, ia akan berusaha berbuat sekuat tenaga untuk mewujudkan apa yang 
diinginkannya. Namun belum tentu upaya yang keras itu akan menghasilkan produktivitas yang diharapkan, apabila tidak disalurkan dalam arah yang dikehendaki organisasi.

Unsur kebutuhan berarti suatu keadaan internal yang menyebabkan hasil-hasil tertentu tampak menarik. Suatu kebutuhan yang tidak terpuaskan akan menciptakan tegangan yang merangsang dorongan-dorongan didalam diri individu. Dorongan ini menimbulkan suatu perilaku pencarian untuk menemukan tujuantujuan tertentu yang apabila tercapai akan memenuhi kebutuhan itu dan mendorong ke pengurangan tegangan.

Selain kepemimpinan dan motivasi, lingkungan kerja juga merupakan salah satu faktor yang berpengaruh terhadap kepuasan karyawan. Lingkungan kerja adalah keseluruhan alat perkakas dan bahan yang dihadapi, lingkungan sekitarnya dimana seseorang bekerja, metode kerjanya, serta pengaturan kerjanya baik sebagai perseorangan maupun sebagai kelompok. Sedarmayanti (2009)

Dapat ditarik kesimpulan bahwa para karyawan akan merasa puas dengan kondisi lingkungan kerja yang baik, dan hal itu akan menunjang produktivitas karyawan yang pada akhirnya berdampak pada kenaikan tingkat kinerja karyawan.

Konsekuensinya, perusahaan akan mengalami kendala apabila ketidakpuasan dirasakan oleh para karyawan dan akan menimbulkan hal-hal yang tidak diinginkan oleh perusahaan. Misalnya adanya aksi mogok kerja, turunnya kinerja karyawan, kemangkiran, dan lain-lain. Yang pada akhirnya kinerja perusahaan secara global akan menurun. Maka dari itu, untuk meningkatkan kinerja dan kepuasan karyawan, pimpinan sebaiknya mengerti apa yang dibutuhkan dan diinginkan oleh karyawan.

PT. Karwikarya Wisman Graha Tanjungpinang adalah perusahaan yang bergerak dibidang tekstil yang memproduksi pakaian jadi. Bahan baku yang digunakan berasal dari produk impor maupun local. Kegiatan utama perusahaan ini adalah memproduksi jenis pakaian yang siap pakai, yang kemudian hasil produksinya di impor ke luar negri.

Berdasarkan fenomena diatas, kemungkinan gaya kepemimpinan yang diterapkan di PT. Karwikarya Wisman Graha Tanjungpinang adalah kepemimpinan delegatif, yaitu jika seorang pemimpin mendelegasikan wewenang kepada bawahannya dengan agak lengkap, sehingga bawahan itu dapat mengambil keputusan dan kebijakan-kebijakan dengan agak bebas dan leluasa dalam melaksanakan. Kelemahan dari gaya kepemimpinan ini, Hubungan kepada atasan dirasakan kurang baik, jarang terjadinya kontak atau hubungan antara atasan dengan bawahannya, khususnya dibidang produksi.

Dalam hal motivasi, karyawan merasakan kurangnya pengakuan dari atasan. hal ini disebabkan kurangnya pengetahuan karyawan dalam menyelesaikan pekerjaannya. Untuk itu karyawan membutuhkan program pelatihan dan keterampilan serta pengetahuan karyawan dalam menyelesaikan pekerjaan masingmasing sehingga hambatan dan kesalahan tidak lagi terjadi dalam menyelesaikan pekerjaan.

Lingkungan kerja dirasakan tidak memadainya .Masih ada karyawan yang membawa masalah pribadi ke tempat kerja sehingga hubungan dengan rekan kerja bisa menimbulkan ketegangan dan akan mudah melampiasakan kemarahannya serta mudah tersinggung. Hal ini akan menganggu produktifitas kerja dan mengakibatkan menurunnya kinerja.

Dalam hal ini sangat berpengaruh terhadap kepuasan kerja karyawan,

kurangnya motivasi diri dan motivasi dari pimpinan mengingatkan pentingnya motivasi 
kepada karyawan sehingga dapat mencapai tujuan organisasi secara maksimal. Berdasarkan penelitian awal tersebut dapat diprediksi kepuasan kerja karyawan pada PT. Karwikarya Wisman Graha menurun. Hal ini kemungkinan karena gaya kepemimpinan, motivasi kerja dan lingkungan kerja di perusahaan PT. Karwikarya Wisman Graha Tanjungpinang.

Berdasarkan latar belakang diatas, penulis tertarik untuk melakukan penelitian yang berjudul “ Pengaruh Gaya Kepemimpinan, Motivasi Kerja dan Lingkungan Kerja Terhadap Kepuasan Kerja Karyawan PT - Karwikarya Wisman Graha Tanjungpinang”.

\section{PERUMUSAN MASALAH}

Rumusan masalah pada penelitian ini adalah :

1. Apakah gaya kepemimpinan berpengaruh secara parsial terhadap kepuasan kerja karyawan pada PT. Karwikarya Wisman Graha Tanjungpinang?

2. Apakah motivasi kerja berpengaruh secara parsial terhadap kepuasan kerja karyawan pada PT. Karwikarya Wisman Graha Tanjungpinang ?

3. Apakah lingkungan kerja berpengaruh secara parsial terhadap kepuasan kerja karyawan PT. Karwikarya Wisman Graha Tanjungpinang?

4. Apakah gaya kepemimpinan, motivasi kerja dan lingkungan kerja berpengaruh secara simultan terhadap kepuasan kerja karyawan pada PT. Karwikarya Wisman Graha Tanjungpinang?

\section{TUJUAN PENELITIAN}

Adapun tujuan penelitian berdasarkan rumusan masalah adalah sebagai berikut :

1. Untuk mengetahui pengaruh gaya kepemimpinan secara parsial terhadap kepuasan kerja karyawan pada PT. Karwikarya Wisman Graha Tanjungpinang.

2. Untuk mengetahui pengaruh motivasi kerja secara parsial terhadap kepuasan kerja karyawan pada PT. Karwikarya Wisman Graha Tanjungpinang.

3. Untuk mengetahui pengaruh lingkungan kerja secara parsial terhadap kepuasan kerja karyawan PT. Karwikarya Wisman Graha Tanjungpinang.

4. Untuk mengetahui pengaruh gaya kepemimpinan, motivasi kerja dan lingkungan kerja secara simultan terhadap kepuasan kerja karyawan PT. Karwikarya Wisman Graha Tanjungpinang.

\section{KAJIAN PUSTAKA \\ Gaya Kepemimpinan}

Menurut Prasetyo dalam Restu Adi Nugroho, Sri Hartono, Sudarwati (2016) norma perilaku yang dipergunakan untuk mempengaruhi orang lain sesuai dengan keinginannya merupakan gaya kepemimpinan. Gaya kepemimpinan merupakan bentuk perilaku yang dapat dibuat mengintegrasikan tujuan dengan tujuan individu.

\section{Motivasi kerja}

Menurut Edwin B Flippo dalam Hasibuan (2005 : 143) "Direction or motivation is essence, it is a skill in aligning employee and organization interest so that behavior result in achievement of employee want simultaneously with attaintment or organizational objectives". (Motivasi kerja adalah suatu keahlian, dalam mengarahkan pegawai dan organisasi agar mau bekerja secara berhasil, sehingga keinginan para pegawai atau tujuan organisasi sekaligus tercapai).

\section{Lingkungan Kerja}

Lingkungan kerja dapat diartikan 
sebagai kekuatan-kekuatan yang memengaruhi, baik secara langsung maupun tidak langsung terhadap karyawan organisasi maupun perusahaan ( Terry,2006).

\section{Kepuasan Kerja}

Tiffin dalam Hartatik (2014) mengungkapkan bahwa pekerjaan, situasi kerja, dan kerjasama antara pimpinan dengan karyawan berhubungan erat dengan kepuasan kerja. Kepuasan kerja adalah sikap positif atau negative yang dilakukan individu terhadap pekerjaannya.

\section{HIPOTESIS}

Berdasarkan permasalahan dan kajian pustaka yang telah dikemukakan sebelumnya, maka penulis merumuskan hipotesis sebagai berikut:

1. Adanya hubungan gaya kepemimpinan secara parsial terhadap kepuasan kerja pada PT. Karwikarya Wisman Graha Tanjungpinang

2. Adanya hubungan motivasi kerja secara parsial terhadap kepuasan kerja pada PT. Karwikarya Wisman Graha Tanjungpinang.

3. Adanya hubungan lingkungan kerja secara parsial terhadap kepuasan kerja pada PT. Karwikarya Wisman Graha Tanjungpinang

4. Adanya hubungan gaya kepemimpinan, motivasi kerja dan lingkungan kerja secara silmutan terhadap kepuasan kerja pada PT. Karwikarya Wisman Graha Tanjungpinang.

\section{METODE PENELITIAN}

Metode yang digunakan dalam penelitian ini yaitu metode deskriptif dengan tujuan menggambarkan keadaan subjek atau objek dalam penelitian berupa orang, lembaga masyarakat dan yang lainnya pada saat sekarang berdasarkan fakta.

Menurut Sukmadinata (2006: 71) menjelaskan bahwa Penelitian deskriptif adalah salah satu jenis penelitian yang ditujukan untuk untuk mendeskripsikan fenomena-fenomena yang ada, baik fenomena alamiah maupun fenomena buatan manusia. Fenomena ini bisa berupa bentuk, aktifitas, karakteristik, perubahan, hubungan, kesamaan dan perbedaan antara fenomena yang satu dengan fenomena yang lainnya

Penelitian ini bersifat kuantitatif yaitu penelitian berdasarkan angka-angka dalam memecahkan masalah. Penelitian ini menggunakan skala likert yaitu menyusun pertanyaan atau pernyataan yang masingmasing item diberi range skor dalam skala likert. Skala likert digunakan untuk mengukur sikap, pendapat, persepsi seseorang atau kelompok tentang fenomena sosial.

\section{Metode Penentuan Populasi Dan Sampel Populasi}

Menurut Istijanto (2005:109) populasi diartikan sebagai jumlah keseluruhan semua anggota yang diteliti. Populasi adalah keseluruhan jumlah yang terdiri atas objek atau subjek yang mempunyai karakteristik dan kualitas tertentu yang di terapkan oleh peneliti untuk diteliti dan kemudian di tarik kesimpulannya (Sujarweni:2015: 82 ). Populasi yang akan digunakan dalam penelitian ini adalah 162 karyawan.

\section{Sampel}

Untuk sampel atau jumlah sampel yang diambil merupakan hal yang penting jika peneliti melakukan penelitian yang menggunakan analisis kuantitatif. Dalam penelitian ini, teknik pengambilan sampel menggunakan rumus slovin dari Sujarweni ( $2015: 82$ ) yaitu sebagai berikut:

$$
\mathbf{n}=\frac{N}{1+N e^{2}}
$$

Berdasarkan rumus tersebut, jumlah sampel yang diperoleh untuk penelitian ini 
dengan nilai presisi yang ditetapkan sebesar $5 \%$. Maka jumlah sampel dalam penelitian ini adalah 115 karyawan bagian produksi PT. Karwikarya Wisman Graha Tanjungpinang.

\section{HASIL PENELITIAN DAN PEMBAHASAN}

\section{Analisis Statistik Deskriptif}

Statistic deskriptif digunakan untuk menggambarkan secara statistic dari variabel yang ada dalam penelitian ini, dilihat nilai minimum, maksimum, mean, dan standar deviasi. Ghozali (2013:19)

\section{Tabel 1}

Descriptive Statistics

\begin{tabular}{|l|r|r|r|r|c|}
\hline & $\mathrm{N}$ & Min & Max & Mean & $\begin{array}{c}\text { Std. } \\
\text { Deviatio } \\
\mathrm{n}\end{array}$ \\
\hline Gaya.Kep & 115 & 27 & 54 & 42.71 & 6.530 \\
\hline Motivasi & 115 & 30 & 59 & 46.57 & 7.134 \\
\hline Lingkungan & 115 & 27 & 54 & 42.30 & 6.661 \\
\hline Kepuasan & 115 & 36 & 69 & 54.27 & 8.143 \\
\hline $\begin{array}{l}\text { Valid N } \\
\text { (Listwise) }\end{array}$ & 115 & & & & \\
\hline
\end{tabular}

Sumber: data diolah, 2017

\section{Pengujian Hipotesis}

\section{Uji T ( parsial )}

Hipotesis $\mathrm{x} 1$, $\mathrm{x} 2$ dan $\mathrm{x} 3$ dalam penelitian ini diuji kebenarannya dengan menggunakan uji parsial. Pengujian dilakukan dengan melihat taraf signifikansi (p-value), jika taraf signifikansi yang dihasilkan dari perhitungan di bawah 0,05 maka hipotesis diterima, sebaliknya jika taraf signifikansi hasil hitung lebih besar dari 0,05 maka hipotesis ditolak.

Tabel 5

Hasil Uji t

\begin{tabular}{|l|l|c|r|}
\hline \multicolumn{2}{|c|}{ Variabel bebas } & t & \multicolumn{1}{c|}{ Sig. } \\
\hline 1 & (Constant) & 3.297 & .001 \\
\hline & Gaya_Kepemimpinan & 3.171 & .002 \\
\hline & Motivasi & 2.366 & .020 \\
\hline \multicolumn{2}{|c|}{ Lingkungan_Kerja } & 7.168 & .000 \\
\hline \multicolumn{2}{|l|}{ a. Dependent Variable: KEPUASAN_KERJA } \\
\hline
\end{tabular}

Sumber: data diolah, 2017

\section{Pengaruh Variabel Motivasi Kerja (X2)} Terhadap Kepuasan Kerja Karyawan (Y)

Variabel motivasi kerja dengan $t_{\text {hitung }}$ $(2,366)>t_{\text {tabel }}(1,981)$ terlihat bahwa terdapat pengaruh antara variabel motivasi kerja dengan variabel kepuasan kerja. Hasil pengujian hipotesis motivasi kerja menunjukkan nilai $\mathrm{t}$ hitung sebesar 2,366 dengan taraf signifikansi 0,020. Taraf signifikansi tersebut lebih kecil dari 0,05, yang berarti bahwa hipotesis dalam penelitian ini menolak Ho dan menerima Ha. Dengan demikian bahwa hipotesis H2 " Motivasi Kerja mempunyai pengaruh positif dan signifikan terhadap kepuasan kerja”.

\section{Pengaruh Variabel Lingkungan Kerja (X3) Terhadap Kepuasan Kerja Karyawan (Y)}

Variabel gaya kepemimpinan dengan $t_{\text {hitung }}$ $(7,168)>t_{\text {tabel }}(1,981)$ terlihat bahwa terdapat pengaruh antara variabel lingkungan kerja dengan variabel kepuasan kerja. Hasil pengujian hipotesis lingkungan kerja menunjukkan nilai $\mathrm{t}$ hitung sebesar 7,168 dengan taraf signifikansi 0,000. Taraf signifikansi tersebut lebih kecil dari 0,05 , yang berarti bahwa hipotesis dalam penelitian ini menolak Ho dan menerima Ha. Dengan demikian dapat berarti bahwa hipotesis H3 “ lingkungan kerja mempunyai pengaruh positif dan signifikan terhadap kepuasan kerja”.

\section{Uji F ( simultan)}

Pengujian pengaruh secara simultan gaya kepemimpinan, motivasi kerja dan 
lingkungan kerja terhadap kepuasan kerja menunjukkan nilai sebagai berikut:

Tabel 6

Hasil Uji F

\begin{tabular}{|c|c|c|c|c|c|c|}
\hline \multicolumn{7}{|c|}{ ANOVAa $^{a}$} \\
\hline \multicolumn{2}{|c|}{ Model } & $\begin{array}{l}\text { Sum of } \\
\text { Squares }\end{array}$ & Df & Mean & $\mathrm{F}$ & Sig. \\
\hline 1 & Regression & 7468.334 & 3 & 2489.445 & \multirow{3}{*}{$\begin{array}{l}3059.7 \\
80\end{array}$} & \multirow{3}{*}{$7.000^{b}$} \\
\hline & Residual & 90.310 & 111 & .814 & & \\
\hline & Total & 7558.643 & 114 & & & \\
\hline
\end{tabular}

Sumber: data diolah, 2017

Dari tabel diatas menunjukkan bahwa penetapan dalam metode ini adalah, jika nilai $\mathrm{t}$ hitung $>\mathrm{t}$ tabel maka hipotesis penelitian di terima, dan sebaliknya. Nilai $F_{\text {hitung }}=3059.780$ $>\mathrm{F}_{\text {tabel }}=2,69$ dan taraf signifikan $0,000<$ 0,05 . artinya bahwa hipotesis yang menyatakan bahwa secara simultan variabel gaya kepemimpinan, motivasi kerja dan lingkungan kerja mempunyai pengaruh yang positif terhadap kepuasan kerja. Hipotesis dalam penelitian ini menolak $\mathrm{H}_{0}$. Nilai signifikan tersebut menunjukkan gaya kepemimpinan, motivasi kerja dan lingkungan kerja secara bersama-sama memiliki pengaruh terhadap kepuasan kerja.

\section{Uji Determinasi ( $\left.R^{2}\right)$}

Koefisien determinasi $\left(\mathrm{R}^{2}\right)$ mengukur seberapa jauh kemampuan model dalam menerangkan variasi variabel terkait ( Ghozali, 2013 ).

Tabel 7

Uji Determinan

\begin{tabular}{|l|c|l|r|r|}
\hline \multicolumn{5}{|c|}{ Model Summary $^{\mathbf{b}}$} \\
\cline { 1 - 1 } Model & R & R Square & $\begin{array}{c}\text { Adjusted R } \\
\text { Square }\end{array}$ & Std. Error \\
\hline 1 & $.994^{\mathrm{a}}$ & .988 & .988 & .902 \\
\hline
\end{tabular}

Sumber: data diolah, 2017

Berdasarkan tabel diatas hasil dari adjusted $R^{2}$ (koefisien determinasi) menunjukkan nilai sebesar 0,988. Hasil ini mengindikasikan bahwa 98,8 persen kepuasan kerja karyawan dipengaruhi oleh gaya kepemimpinan (gaya kepemimpinan otoriter, partisipatif, dan delegatif), motivasi kerja (kebutuhan fisiologis, kebutuhan rasa aman, kebutuhan sosial, kebutuhan penghargaan, dan kebutuhan aktualisasi diri), dan lingkungan kerja (lingkungan kerja fisik dan non fisik) sedangkan 1,2 persen dipengaruhi oleh variabel lain yang tidak diteliti.

\section{KESIMPULAN}

Berdasarkan hasil penelitian dari pengaruh gaya kepemimpinan, motivasi kerja dan Lingkungan Kerja terhadap Kepuasan Kerja Karywan PT. Karwikarya Wisman Graha Tanjungpinang maka dapat diambil kesimpulan sebagai berikut

1. Secara parsial motivasi berpengaruh positif terhadap kepuasan kerja karyawan PT. Karwikarya Wisman Graha Tanjungpinang. Hal ini sesuai dengan hipotesis bahwa gaya kepemimpinan variabel gaya kepemimpinan dengan $t_{\text {hitung }}$ $(3,171)>t_{\text {tabel }}(1,981)$ berpengaruh positif terhadap kepuasan kerja karyawan.

2. Secara parsial motivasi kerja berpengaruh positif terhadap kepuasan kerja karyawan PT. Karwikarya Wisman Graha Tanjungpinang. Hal ini sesuai dengan hipotesis bahwa motivasi kerja ditunjukkan dengan nilai $t_{\text {hitung }}(2.366)>$ $\mathrm{t}_{\text {tabel }}(1,981)$ berpengaruh positif terhadap kepuasan kerja karyawan.

3. Secara parsial lingkungan kerja berpengaruh positif terhadap kepuasan kerja karyawan PT. Karwikarya Wisman Graha Tanjungpinang. Hal ini sesuai dengan hipotesis bahwa lingkungan kerja dengan nilai $t_{\text {hitung }}(7.168)>t_{\text {tabel }}(1,981)$ berpengaruh positif terhadap kepuasan kerja karyawan.

4. Secara simultan menunjukkan bahwa gaya kepemimpinan, motivasi kerja dan lingkungan kerja mempunyai pengaruh 
terhadap kepuasan kerja karyawan PT.Karwikarya Wisman Graha Tanjungpinang. Hal ini sesuai dengan hipotesis bahwa gaya kepemimpinan, motivasi kerja dan lingkungan kerja dengan nilai $\mathrm{F}_{\text {hitung }}=3059.780>\mathrm{F}_{\text {tabel }}=$ 2,69 dan taraf signifikan $0,000<0,05$ mempunyai pengaruh terhadap kepuasan kerja karyawan

\section{SARAN}

Berdasarkan hasil penelitian dan kesimpulan diatas, maka diberikan saran sebagai berikut :

1. PT. Karwikarya Wisman Graha Tanjungpinang yang menjadi objek penelitian tetap menjaga kepuasan kerja karyawan agar tercapainya visi dan misi

perusahaan.

2. Bagi manajemen sumber daya manusia PT. Karwikarya Wisman Graha Tanjungpinang yang menjadi objek penelitian, selalu memberikan perhatian dan dukungan yang lebih terhadap karyawan, agar perusahaan dapat berjalan sebagaimana visi dan misi perusahaan.

3. Dalam penelitian yang akan datang perlunya memperluas jangkauan objek

penelitian, yang mana pada penelitian ini hanya mengambil objek pada PT. Karwikarya Wisman Graha Tanjungpinang

4. Untuk peneliti yang akan datang perlu meningkatkan dan mengembangkan populasi dan sampel penelitian, sehingga data yang lebih kompleks dan dapat terbaca dengan mudah.

\section{DAFTAR PUSTAKA}

Dhermawan Bagus Ngurah Agung Anak, Sudibya Adnyana I Gde, Utama
Mudiartha Wayan I (2012). Motivasi Dan Lingkungan Kerja, Kompetensi Dan Kompensasi terhadap kepuasan kerja kinerja pegawai Dan Kinerja Pegawai Di Lingkungan Kantor Dinas Pekerjaan Umum Provinsi Bali.

Ghozali, Imam. (2013). Aplikasi Analisis Multivariate dengan Program IBM SPSS 21. Semarang : Undip

Hartatik, I.P. (2014). Buku Praktis Pengembangkan SDM.Yogyakarta

Laksana Hasibuan, M.S.P. (2005). Manajemen Sumber Daya Manusia. Bandung : Bumi Askara Hasibuan, M.S.P. 2004. Dasar, Pengertian, dan Masalah. Jakarta : Bumi Askara

Ismail Hasan, Rahmawati Rini (2014). Pengaruh Gaya Kepemimpinan Dan Motivasi Kerja Terhadap Kepuasan Kerja Karyawan (Studi Pada Politeknik Tanah Laut Di Kabupaten Tanah Laut)

Istijanto. (2005). Riset Sumber Daya Manusia. Jakarta : PT Gramedia Pustaka Utama

Kinanti Queentarina Annisa (2012). Hubungan Lingkungan Kerja Dengan Kepuasan Kerja Pada Devisi Sumber Daya Manusia PT. Suveryor Indonesia.

Lomanto Losiana Silvia (2012). Pengaruh Gaya Kepemimpinan Terhadap Kepuasan Kerja Dengan Moderasi Locus Of Control Dan Kejelasan Tugas Pada Peran Auditor Yunior

Luthans.F. (2006). Perilaku Organisasi Edisi 10 .Yogyakarta : Andi

Noor, juliansyah. (2012). Analisis Data Penelitian Ekonomi Manajemen, Jakarta : Grasindo Nugroho Adi Restu, Hartono Sri, Sudarwati (2016). Pengaruh Komitmen Organisasi, Motivasi 
Berprestasi Dan Gaya Kepemimpinan Terhadap Kinerja Karyawan Pt Wangsa Jatra Lestari 194 Jurnal Bisnis Dan Ekonomi (Jbe), September 2016, Hal. 194 - 203 Vol. 23, No. 2 Issn: 1412-3126

Ramlawati (2016). Analisis Pengaruh Gaya Kepemimpinan Dan Motivasi Kerja Terhadap Kinerja Karyawan Di Stie Amkop Makassar Vol. 11 No.3 Okt-Des 2016 [Jurnal Capacity Stie Amkop Makassar] Issn : 1907-3313 Website Http://Journal.Stieamkop.Ac.Id/

Rizal Fitriana (2015). Lingkungan Kerja, Kompensasi terhadap Kepuasan kerja Karyawan Pada PT. Statika Mitrasarana Padang.

Robbins.S.P \& Judge.T.A. (2008). Perilaku Organisasi Organizational Behavior. Jakarta : Salemba Empat

Sedarmayanti (2009).Tata Kerja dan Produktivitas Kerja.Bandung : CV. Mandar Maju

Sinambela, L.P. (2016). Manajemen Sumber Daya Manusia. Jakarta : PT. Bumi Askara

Sujarweni, V.W. (2016). Metodologi Penelitian. Yogyakarta : Pustaka Barupress

Sunardi \& Primastiwi, Anita. (2012). Bisnis Pengantar ( Konsep, Strategi, \& Kasus). Yogyakarta: CAPS

Surbakti, E.B.(2012). Panduan Lengkap Manajemen Perusahaan. Jakarta : Praninta Askara

Sutrisno,Edi. (2009). Manajemen Sumber Daya Manusia. Jakarta : Kencana

Terry, G.R \& Rue, L.W. (2012). Dasar-Dasar Manajemen. Jakarta : PT. Bumi Askara
Torang. Syamsir.2016. Organisasi \& Manjemen. Bandung : ALFABETA.cv

Wibowo,A.E. (2012). Aplikasi Praktis SPSS dalam Penelitian.Yogyakarta: Penerbit Gava Media.

Wibowo Mukti, Musadieq Al Mochammad, Nurtjahjono Eko Gunawan (2014). Lingkungan kerja terhadap kepuasan kerja Karyawan (Studi Pada Karyawan Pt.Telekomunikasi Indonesia Tbk. Kandatel Malang). 